\title{
HLA-DQ2 and -DQ8 signatures of gluten T cell epitopes in celiac disease
}

\author{
Stig Tollefsen, ${ }^{1}$ Helene Arentz-Hansen, ${ }^{1}$ Burkhard Fleckenstein, ${ }^{1}$ Øyvind Molberg, ${ }^{1,2}$ \\ Melinda Ráki, ${ }^{1}$ William W. Kwok, ${ }^{3}$ Günther Jung, ${ }^{4}$ Knut E.A. Lundin,1,5 and Ludvig M. Sollid1

\begin{abstract}
${ }^{1}$ Institute of Immunology, University of Oslo, Rikshospitalet-Radiumhospitalet Medical Center, Oslo, Norway. ${ }^{2}$ Department of Rheumatology, Rikshospitalet-Radiumhospitalet Medical Center, Oslo, Norway. ${ }^{3}$ Benaroya Research Institute, Seattle, Washington, USA. ${ }^{4}$ Institute of Organic Chemistry, University of Tübingen, Tübingen, Germany. ${ }^{5}$ Department of Medicine, Rikshospitalet-Radiumhospitalet Medical Center, Oslo, Norway.
\end{abstract}

\begin{abstract}
Celiac disease is associated with HLA-DQ2 and, to a lesser extent, HLA-DQ8. Type 1 diabetes is associated with the same DQ molecules in the opposite order and with possible involvement of trans-encoded DQ heterodimers. $T$ cells that are reactive with gluten peptides deamidated by transglutaminase 2 and invariably restricted by $\mathrm{DQ} 2$ or DQ8 can be isolated from celiac lesions. We used intestinal T cells from celiac patients to map DQ2 and DQ8 epitopes within 2 representative gluten proteins, $\alpha$-gliadin AJ133612 and $\gamma$-gliadin M36999. For $\alpha$-gliadin, DQ2- and DQ8-restricted T cells recognized deamidated peptides of 2 separate regions. For $\gamma$-gliadin, DQ2-and DQ8-restricted $T$ cells recognized deamidated peptides of the same region. Some $\gamma$-gliadin peptides were recognized by T cells in the context of DQ2 or DQ8 when bound in exactly the same registers, but with different requirements for deamidation; deamidation at peptide position 4 (P4) was important for DQ2-restricted T cells, whereas deamidation at $\mathrm{P} 1$ and/or $\mathrm{P} 9$ was important for DQ8-restricted T cells. Peptides combining the DQ2 and DQ8 signatures could be presented by DQ2, DQ8, and trans-encoded DQ heterodimers. Our findings shed light on the basis for the HLA associations in celiac disease and type 1 diabetes.
\end{abstract}

\section{Introduction}

Celiac disease is a chronic disease of the small intestine caused by an inappropriate immune response to ingested wheat gluten proteins and related proteins in barley and rye $(1,2)$. The celiac lesion is characterized by villous atrophy, crypt hyperplasia, and a dense infiltration of lymphocytes in the epithelium and lamina propria. A significant proportion of the genetic predisposition comes from MHC-linked (HLA-linked) genes, estimated to account for about $50 \%$ of the genetic load (3). Indeed, more than $90 \%$ of celiac patients carry a variant of DQ2, encoded by $D Q A 1 * 05 / D Q B * 02$, whereas most of the remaining patients carry DQ8, encoded by $D Q A 1 * 03$ / $D Q B 1 * 0302(2,3)$. The strong HLA association implies a central role for $\mathrm{CD}^{+} \mathrm{T}$ cells in disease pathogenesis. In fact, $\mathrm{CD} 4^{+}$gluten-specific $\mathrm{T}$ cells can be readily isolated from small intestinal biopsies of celiac patients, but not from healthy controls $(4,5)$. Strikingly, these T cells are exclusively restricted by the DQ2 or DQ8 molecules $(4,6)$, strongly indicating that the DQ2 and DQ8 molecules are important peptide-presenting molecules in this disease. The great majority of the gluten-specific $\mathrm{T}$ cells recognize gluten only - or better - after the gluten antigen has been modified by transglutaminase 2 (TG2) $(7,8)$. This enzyme catalyzes an ordered deamidation of certain glutamine residues by converting them to glutamate residues. Both DQ2 and DQ8 have preferences for binding of peptide ligands with multiple negatively charged residues (9-13). Several epitopes have been identified, and much has been learned about T cell epitopes recognized by DQ2-restricted T cells (14-19); conversely, our understanding of DQ8-restricted gluten T cell epitopes is more limited, as only 2 epitopes have been identified so far $(20,21)$. Commonly, all the DQ2- and DQ8-restricted intestinal T

Nonstandard abbreviations used: MS, mass spectrometry; P1, peptide position 1; TG2, transglutaminase 2 .

Conflict of interest: The authors have declared that no conflict of interest exists. Citation for this article: J. Clin. Invest. 116:2226-2236 (2006). doi:10.1172/JCI27620. cell epitopes have been defined from $\mathrm{T}$ cells that are derived from intact celiac lesion biopsies stimulated ex vivo with enzymatically digested (i.e., via pepsin/trypsin or chymotrypsin) gluten. The main effect of performing such an ex vivo antigen challenge is to enrich for $T$ cells specific for the challenging antigen. Thus the possibility cannot be excluded that the enzymatic pretreatment of the gluten antigen introduces a bias by limiting the number of gluten peptide sequences available for in situ activation of the $\mathrm{T}$ cells within the biopsy specimen. To ensure an unbiased representation of gluten peptides, we established a number of independent $T$ cell lines from biopsies challenged with a digest of whole gluten, with a digest of a recombinant gliadin protein ( $\alpha$-gliadin AJ133612), and with overlapping peptides spanning the whole sequence of the same recombinant protein. Having confirmed the methods to give full representation of the epitopes, we proceeded to compare the reactivity patterns of $T$ cell lines of celiac disease patients with different HLA types to 2 prototype gliadins ( $\alpha$-gliadin AJ133612 and $\gamma$-gliadin M36999). Interestingly, DQ2 and DQ8 employed different rules for selection of epitopes for $\mathrm{T}$ cell presentation. We identified $2 \gamma$-gliadin peptides recognized in the same binding register when presented by DQ2 or DQ8 molecules, but the requirement for glutamine residues to be deamidated by TG2 differed between the DQ2-restricted and the DQ8-restricted T cells. These findings further increase our understanding of the molecular basis for HLA association in celiac disease. Moreover, the results are relevant for type 1 diabetes. This disease is also associated with the DQ2 and DQ8 molecules, in particular when these 2 molecules occur together (in DQ2/DQ8 heterozygous individuals), suggesting that transencoded DQ heterodimers may be important peptide-presenting molecules in type 1 diabetes (22-27). In contrast to celiac disease, the antigen eliciting type 1 diabetes is as yet unidentified. Thus the rules dictating $\mathrm{T}$ cell recognition of gluten peptides in the context of DQ2 and DQ8 can provide clues to understand the hallmarks of antigenic peptide(s) that can elicit type 1 diabetes. 


\section{Table 1}

Amino acid sequences of the peptides in AJ133612 $\alpha$-gliadin and M36999 $\gamma$-gliadin that elicited a positive T cell response

\begin{tabular}{|c|c|}
\hline Peptide & Sequence \\
\hline \multicolumn{2}{|c|}{ AJ133612 $\alpha$-gliadin } \\
\hline 1420 & 56YLQLQPFPQPQLPYP70 \\
\hline 1421 & ${ }^{61} P F P Q P Q L P Y P Q P Q L P 75$ \\
\hline 1422 & ${ }^{66} \mathrm{QLPYPQPQLPYPQPQ}{ }^{80}$ \\
\hline 1423 & ${ }^{71}$ QPQLPYPQPQLPYPQ85 \\
\hline 1424 & ${ }^{76} Y P Q P Q L P Y P Q P Q P F R 90$ \\
\hline 1447 & ${ }^{226 Y P S G Q G S F Q P S Q Q N P 240 ~}$ \\
\hline 1448 & ${ }^{231}$ GSFQPSQQNPQAQGS 245 \\
\hline 1450 & ${ }^{241}$ QAQGSVQPQQLPQFE 255 \\
\hline \multicolumn{2}{|c|}{ M36999 $\gamma$-gliadin } \\
\hline 1370 & ${ }^{11} W P Q Q Q P F P Q P Q Q P F C Q Q P Q R^{30}$ \\
\hline 1371 & ${ }^{21} Q Q P F C Q Q P Q R T I P Q P H Q T F H 40$ \\
\hline 1372 & ${ }^{31}$ TIPQPHQTFHHQPQQTFPQP50 \\
\hline 1373 & ${ }^{41} \mathrm{HQPQQTFPQPQQTYPHQPQQ60}$ \\
\hline 1374 & ${ }^{51} Q Q T Y P H Q P Q Q Q F P Q T Q Q P Q Q 70$ \\
\hline 1375 & ${ }^{61} Q F P Q T Q Q P Q Q P F P Q P Q Q T F P 80$ \\
\hline 1376 & ${ }^{71} \mathrm{PFPQPQQTFPQQPQLPFPQQ}{ }^{90}$ \\
\hline 1377 & 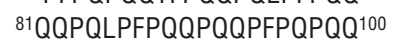 \\
\hline 1378 & ${ }^{91} P Q Q P F P Q P Q Q P Q Q P F P Q S Q Q 110$ \\
\hline 1379 & ${ }^{101} P Q Q P F P Q S Q Q P Q Q P F P Q P Q Q 120$ \\
\hline 1380 & ${ }^{111} P Q Q P F P Q P Q Q Q F P Q P Q Q P Q Q{ }^{130}$ \\
\hline 1381 & ${ }^{121} Q F P Q P Q Q P Q Q S F P Q Q Q Q P A I^{140}$ \\
\hline 1382 & ${ }^{131}$ SFPQQQQPAIQSFLQQQMNP150 \\
\hline 1383 & ${ }^{141}$ QSFLQQQMNPCKNFLLQQCN 160 \\
\hline 1388 & ${ }^{201}$ IHSVAHSIIMQQEQQQGVPI220 \\
\hline 1391 & ${ }^{231}$ LGIIQPQQPAQLEGIRSLVL 250 \\
\hline
\end{tabular}

\section{Results}

In vitro challenge of biopsies derived from celiac disease patients with different gluten antigens gives the same T cell response pattern. To test whether the enzymatic treatment of gluten antigen, which was used to stimulate the biopsies, affected epitope mapping and introduced an artificial bias to the confinement of epitopes to proline-rich regions, we first compared the specificity of $\mathrm{T}$ cell lines isolated from biopsies stimulated in parallel with chymotrypsin-digested natural gluten, chymotrypsin-digested recombinant AJ133612 $\alpha$-gliadin, or a panel of overlapping peptides covering the same $\alpha$-gliadin. Multiple intestinal biopsy specimens were obtained from 7 celiac disease patients $\left(4 \mathrm{DQ}^{+} \mathrm{DQ}^{-}, 2 \mathrm{DQ}^{2}{ }^{+} \mathrm{DQ}^{+}\right.$, and $\left.1 \mathrm{DQ}^{2}-\mathrm{DQ}^{+}\right)$and stimulated with distinct antigens. From each biopsy, 4 polyclonal $\mathrm{T}$ cell lines were generated. Gluten-reactive $\mathrm{T}$ cell lines were expanded for 2 weeks and tested against the panel of TG2-treated overlapping peptides of AJ133612 $\alpha$-gliadin.

Parallel T cell lines derived from biopsies stimulated with chymotrypsin-treated gluten, chymotrypsin-treated recombinant AJ133612 $\alpha$-gliadin, and overlapping AJ133612 $\alpha$-gliadin peptides were obtained from 4 of the patients. From the rest of the patients we obtained $\mathrm{T}$ cell lines that were derived from biopsies stimulated with 2 of the 3 antigens. In all cases we found that $T$ cell lines isolated from parallel biopsy specimens stimulated either with chymotrypsin-treated recombinant AJ133612 $\alpha$-gliadin or overlapping AJ133612 $\alpha$-gliadin peptides had nearly identical recognition patterns when tested against the peptide panel (Tables 1 and 2 and Figure 1). The same recognition pattern was also seen for 8 different $\mathrm{T}$ cell lines isolated from biopsy specimens stimu- lated with chymotrypsin-treated gluten (Table 2). In some cases we found that the maximum response of these latter lines was lower than the maximum response of the $\mathrm{T}$ cell lines derived from biopsies stimulated with recombinant gliadin or overlapping peptides (Figure 1). This may reflect the lower concentration of each of the AJ133612 $\alpha$-gliadin peptides in the whole gluten mixture. In essence, the reactivity patterns of the resulting $T$ cell lines were superimposable regardless of which form of antigen was initially used to stimulate the biopsies.

DQ2- and DQ8-restricted T cells recognize peptides in different regions of AJ133612 $\alpha$-gliadin. Interestingly, we found that the DQ2-restricted $\mathrm{T}$ cell responses and the DQ8-restricted T cell responses were localized to 2 separate regions of AJ133612 $\alpha$-gliadin (regions 1 and 2; Figure 2 and Table 2). T cell lines from patients carrying DQ2 or DQ8 were tested against the TG2-treated $\alpha$-gliadin peptides with APCs homozygous for DQ2 or DQ8, respectively. In experiments with $\mathrm{T}$ cell lines derived from $\mathrm{DQ} 2^{+} \mathrm{DQ} 8^{+}$heterozygous patients, the $\alpha$-gliadin peptides were tested for recognition using APCs expressing either DQ2 or DQ8. We found that almost all the DQ2-restricted $\mathrm{T}$ cell responses in $\mathrm{T}$ cell lines derived from the $\mathrm{DQ}^{+}{ }^{+} \mathrm{DQ}^{-}$and $\mathrm{DQ}^{+}{ }^{+} \mathrm{DQ}^{+}$patients were directed toward peptides within the 33-mer peptide fragment in the $\mathrm{N}$-terminal region of AJ133612 $\alpha$-gliadin (region 1). The DQ8-restricted T cell response of $\mathrm{T}$ cell lines obtained from the $\mathrm{DQ} 2-\mathrm{DQ} 8{ }^{+}$patients and 1 of the $\mathrm{DQ}^{+} \mathrm{DQ}^{+}$patients only recognized peptides located in the C-terminal region (region 2; Table 2). The only exception to this pattern was seen in $1 \mathrm{DQ}^{+}{ }^{+} \mathrm{DQ}^{-} \mathrm{T}$ cell line (patient CD510) derived from a biopsy stimulated with overlapping AJ133612 $\alpha$-gliadin peptides, which had a weak response to a peptide in region 2 (stimulation index of 5 compared with the maximum response of 59 toward peptides 1421-1422 within region 1; see Table 2).

By cloning 2 of the $\alpha$-gliadin-reactive DQ8-restricted T cell lines, we obtained $2 \mathrm{~T}$ cell clones (TCC489.2.1.4 and TCC360-HTLR8) that recognized peptide 1447 (226YPSGQGSFQPSQQNP240) of AJ133612 $\alpha$-gliadin, with improved recognition after TG2 treatment of the peptide. Both clones were found to be specific for the previously identified DQ8- $\alpha$-I epitope $(8,20)$. Despite several attempts, we obtained no $\mathrm{T}$ cell clones reactive with peptides 1448 or 1450 , to which some of the $\mathrm{T}$ cell lines were reactive (Table 2 ). To delineate which TG2-mediated deamidations of the DQ8- $\alpha-\mathrm{I}$ epitope were important for recognition by the $\mathrm{T}$ cell clones, we tested peptides with $\mathrm{Q} \rightarrow \mathrm{E}$ substitutions at positions 230 (peptide position 1; P1) and 238 (P9). TCC489.2.1.4 most efficiently recognized the peptide with $\mathrm{Q} \rightarrow \mathrm{E}$ substitutions at both $\mathrm{P} 1$ and P9 (Figure 3A). The peptides with $\mathrm{Q} \rightarrow$ E substitutions at $\mathrm{P} 1$ or P9 alone were less well recognized, yet much more so than the peptide with the native sequence. TCC360-HTLR8 recognized the peptides with $\mathrm{Q} \rightarrow \mathrm{E}$ substitutions at positions $\mathrm{P} 1$ and $\mathrm{P} 9$ and at $\mathrm{P} 9$ alone about equally well (Figure $3 \mathrm{~B}$ ). The peptide with a $\mathrm{Q} \rightarrow \mathrm{E}$ substitution at P1 was recognized less well, but still better than the peptide with the native sequence.

DQ2- and DQ8-restricted T cells recognize peptides in the same region of M36999 $\gamma$-gliadin. Having validated a robust protocol for epitope mapping, we next sought to identify the epitopes that were recognized by DQ2- and DQ8-restricted T cells in $\gamma$-gliadin. We subjected M36999 $\gamma$-gliadin to this analysis. We tested $\mathrm{T}$ cell lines from 9 different celiac patients $\left(2 \mathrm{DQ}^{+} \mathrm{DQ}^{-}, 4 \mathrm{DQ}^{+} \mathrm{DQ}^{+}\right.$, and 3 DQ2-DQ8+; Table 3). The $\mathrm{T}$ cell lines were derived from biopsies stimulated with chymotrypsin-treated gluten (in 7 patients) or with overlapping M36999 $\gamma$-gliadin peptides (in 3 patients; biopsies 


\section{Table 2}

T cell responses to TG2-treated, overlapping AJ133612 $\alpha$-gliadin peptides in intestinal T cell lines derived from 9 adult CD patients

\begin{tabular}{|c|c|c|c|c|c|c|c|c|c|}
\hline \multirow[t]{2}{*}{ Patient } & \multirow[t]{2}{*}{ Stimulant } & \multicolumn{5}{|c|}{ Region 1} & \multicolumn{3}{|c|}{ Region 2} \\
\hline & & 1420 & 1421 & 1422 & 1423 & 1424 & 1447 & 1448 & 1450 \\
\hline \multicolumn{10}{|c|}{ DQ2+DQ8- } \\
\hline \multirow[t]{2}{*}{ CD493 } & Gluten & & $+\mathrm{DQ2}$ & $+\mathrm{DQ} 2$ & $+\mathrm{DQ} 2$ & $+\mathrm{DQ2}$ & & & \\
\hline & $\alpha-G P S$ & $+\mathrm{DQ2}$ & $+\mathrm{DQ} 2$ & $+\mathrm{DQ} 2$ & $+\mathrm{DQ} 2$ & $+\mathrm{DQ} 2$ & & & \\
\hline \multirow[t]{3}{*}{ CD494 } & Gluten & & $+\mathrm{DQ2}$ & $+\mathrm{DQ2}$ & $+\mathrm{DQ} 2$ & & & & \\
\hline & $r-\alpha-g l i$ & & $+\mathrm{DQ2}$ & $+\mathrm{DQ} 2$ & $+\mathrm{DQ} 2$ & $+\mathrm{DQ2}$ & & & \\
\hline & $\alpha-G P s$ & +DQ2 & $+\mathrm{DQ} 2$ & $+\mathrm{DQ} 2$ & +DQ2 & $+\mathrm{DQ} 2$ & & & \\
\hline \multirow[t]{3}{*}{ CD506 } & Gluten & $+\mathrm{DQ} 2$ & $+\mathrm{DQ2}$ & $+\mathrm{DQ} 2$ & $+\mathrm{DQ} 2$ & & & & \\
\hline & $r-\alpha-g l i$ & $+\mathrm{DQ} 2$ & $+\mathrm{DQ2}$ & $+\mathrm{DQ} 2$ & $+\mathrm{DQ} 2$ & $+\mathrm{DQ2}$ & & & \\
\hline & $\alpha$-GPs & +DQ2 & $+\mathrm{DQ} 2$ & $+\mathrm{DQ} 2$ & +DQ2 & $+\mathrm{DQ} 2$ & & & \\
\hline \multirow[t]{2}{*}{ CD510 } & $r-\alpha-g l i$ & $+\mathrm{DQ} 2$ & $+\mathrm{DQ} 2$ & $+\mathrm{DQ} 2$ & $+\mathrm{DQ} 2$ & $+\mathrm{DQ} 2$ & & & \\
\hline & $\alpha-G P S$ & & $+\mathrm{DQ} 2$ & $+\mathrm{DQ} 2$ & $+\mathrm{DQ} 2$ & $+\mathrm{DQ} 2$ & & & $+\mathrm{DQ} 2$ \\
\hline \multicolumn{10}{|c|}{ DQ2+DQ8+ } \\
\hline \multirow[t]{3}{*}{ CD465 } & Gluten & & $+\mathrm{DQ2}$ & $+\mathrm{DQ} 2$ & $+\mathrm{DQ} 2$ & $+\mathrm{DQ} 2$ & & & \\
\hline & $r-\alpha-g l i$ & +DQ2 & $+\mathrm{DQ} 2$ & $+\mathrm{DQ} 2$ & $+\mathrm{DQ} 2$ & $+\mathrm{DQ} 2$ & & & \\
\hline & $\alpha-G P s$ & $+\mathrm{DQ} 2$ & $+\mathrm{DQ} 2$ & $+\mathrm{DQ} 2$ & $+\mathrm{DQ} 2$ & $+\mathrm{DQ} 2$ & & & \\
\hline CD548 & Gluten & $+\mathrm{DQ} 2$ & $+\mathrm{DQ} 2$ & $+\mathrm{DQ} 2$ & $+\mathrm{DQ} 2$ & $+\mathrm{DQ2}$ & & & \\
\hline \multirow[t]{3}{*}{ CD559 } & Gluten & $+\mathrm{DQ} 2$ & $+\mathrm{DQ} 2$ & $+\mathrm{DQ} 2$ & $+\mathrm{DQ} 2$ & $+\mathrm{DQ} 2$ & & & \\
\hline & $r-\alpha-g l i$ & & $+\mathrm{DQ} 2$ & $+\mathrm{DQ} 2$ & $+\mathrm{DQ} 2$ & $+\mathrm{DQ} 2$ & +DQ8 & +DQ8 & +DQ8 \\
\hline & $\alpha-G P s$ & & $+\mathrm{DQ} 2$ & $+\mathrm{DQ} 2$ & $+\mathrm{DQ} 2$ & $+\mathrm{DQ} 2$ & +DQ8 & & \\
\hline \multicolumn{10}{|c|}{ DQ2-DQ8+ } \\
\hline CD360 & Gluten & & & & & & +DQ8 & +DQ8 & +DQ8 \\
\hline \multirow[t]{2}{*}{ CD489 } & Gluten & & & & & & +DQ8 & & \\
\hline & $\mathrm{r}-\alpha-g l i$ & & & & & & +DQ8 & +DQ8 & \\
\hline
\end{tabular}

Shown are positive T cell responses restricted by DQ2 (+DQ2) and DQ8 (+DQ8). Only the peptides of AJ133612 $\alpha$-gliadin that elicited a positive T cell response are indicated. $\alpha$-GPs, $\alpha$-gliadin peptides; $r-\alpha$-gli, recombinant $\alpha$-gliadin.

the DQ2- $\gamma$-VII epitope previously found to be recognized by the DQ2-restricted T cell clone TCC387.19 (19). We thus tested variants of a peptide covering the sequence ${ }^{63}$ PQT QQPQQPFPQPQ ${ }^{76}$ with $\mathrm{Q} \rightarrow \mathrm{E}$ substitutions in positions 66 (P1), 69 (P4), or both (P1/P4) for recognition by the $\mathrm{T}$ cell clones TCC544.1.3.2, TCC544.1.1.2, and TCC387.19 (Figure 5). The 2 DQ8-restricted T cell clones, TCC544.1.1.2 and TCC544.1.3.2, both preferred P1 for recognition. TCC544.1.1.2 recognized the doubly substituted peptide better than the singly substituted peptide (Figure 5A), whereas TCC544.1.3.2 recognized the singly substituted peptide better than the doubly substituted peptide (Figure 5B). The DQ2-restricted clone, TCC387.19, preferred P4 for recognition and also recognized the doubly substituted peptide (Figure 5C).

Electrospray ionization-mass spectrometry (ESI-MS) analysis of peptide 1375 revealed an average deamidation of 1.5 glu-

from 1 patient were treated in parallel with both types of antigens. The $T$ cell lines obtained were next tested against the panel of TG2treated M36999 peptides (Figure 4). The recognition pattern of M36999 $\gamma$-gliadin resembled the recognition pattern of AJ133612 $\alpha$-gliadin in that only peptides in the proline-rich regions were recognized and that $\mathrm{T}$ cell lines derived from biopsies stimulated with gluten or tiled M36999 $\gamma$-gliadin peptides mainly recognized the same individual peptides. However, the response pattern toward M36999 $\gamma$-gliadin differed considerable from that of AJ133612 $\alpha$-gliadin in the way that the DQ2- and DQ8-restricted responses were directed toward the peptides of the same region. Moreover, a higher number of peptides were recognized of M36999 $\gamma$-gliadin than of AJ133612 $\alpha$-gliadin (Table 3).

DQ8-restricted T cell epitopes of M36999 $\gamma$-gliadin. In previous studies, several DQ2-restricted T cell epitopes have been mapped to the proline-rich region of M36999 $\gamma$-gliadin $(18,19)$. In order to identify and characterize DQ8-restricted epitopes, we cloned a T cell line of a $\mathrm{DQ}^{-}{ }^{-} \mathrm{DQ} 8^{+}$patient that was responsive to several peptides of M36999 $\gamma$-gliadin in a TG2-dependent manner. We obtained 2 $\mathrm{T}$ cell clones, TCC544.1.1.2 and TCC544.1.3.2, which both recognized the peptides $1375,1377,1378$, and 1379 after TG2 treatment. These peptides share the sequence QQPQQPFPQ, which we identified to be the P1-P9 core of the epitopes recognized by either of the $\mathrm{T}$ cell clones (data not shown).

DQ2- and DQ8-restricted $T$ cells recognize the same $\gamma$-gliadin epitopes in identical registers but are sensitive to deamidation at different positions. The QQPQQPFPQ sequence is the core part of tamine residues after 4 hours' treatment with TG2. For peptide 1378 , a deamidation of 1.6 residues in average was calculated after treatment for 1.5 hours. MS/MS analysis revealed the following ratios of deamidation for the targeted $Q$ residues: peptide 1375 $\left({ }^{61}\right.$ QFPQTQQPQQPFPQPQQTFP $\left.{ }^{80}\right), 8 \%, 39 \%, 9 \%$, and $44 \%$ for positions 64, 66, 69, and 76, respectively; peptide 1378 ( ${ }^{91} \mathrm{PQQP}-$ FPQPQQPQQPFPQSQQ ${ }^{110}$ ), 39\%, 57\%, and $4 \%$ for positions 92 , 99 , and 102 , respectively. These data suggest that the regional selectivity of TG2 for deamidation is influenced by residues flanking the core region of the $T$ cell epitopes and that deamidation in position P1 is predominantly required for DQ8-restricted recognition of these peptides. Interestingly, both peptides show only little deamidation in position $\mathrm{P} 4$, where deamidation is important for DQ2-restricted recognition.

The sequence QQPQQPFPQ is very similar to the sequence QQPQQPYPQ, which is the core region of the previously characterized DQ2- $\gamma$-III epitope found in AJ416339 $\gamma$-gliadin $(18,19)$. We thus tested the $2 \mathrm{~T}$ cell clones TCC544.1.3.2 and TCC544.1.1.2 against synthetic peptides of AJ416339 $\gamma$-gliadin containing the QQPQQPYPQ sequence and found that they were strongly reactive to these peptides after TG2 treatment. The DQ2- $\gamma$-III-reactive T cell clones TCC430.1.134 and TCC430.1.145 did not recognize any of the $1375,1377,1378$, or 1379 peptides with or without TG2 treatment, probably because they were sensitive to the $\mathrm{F} \rightarrow \mathrm{Y}$ substitution. The reactivity of the DQ2- and DQ8-restricted T cell clones to the fragment ${ }^{66} \mathrm{FPQQPQQPYPQQPQQ}{ }^{80}$ of AJ416339 $\gamma$-gliadin is depicted in Figure 6. 


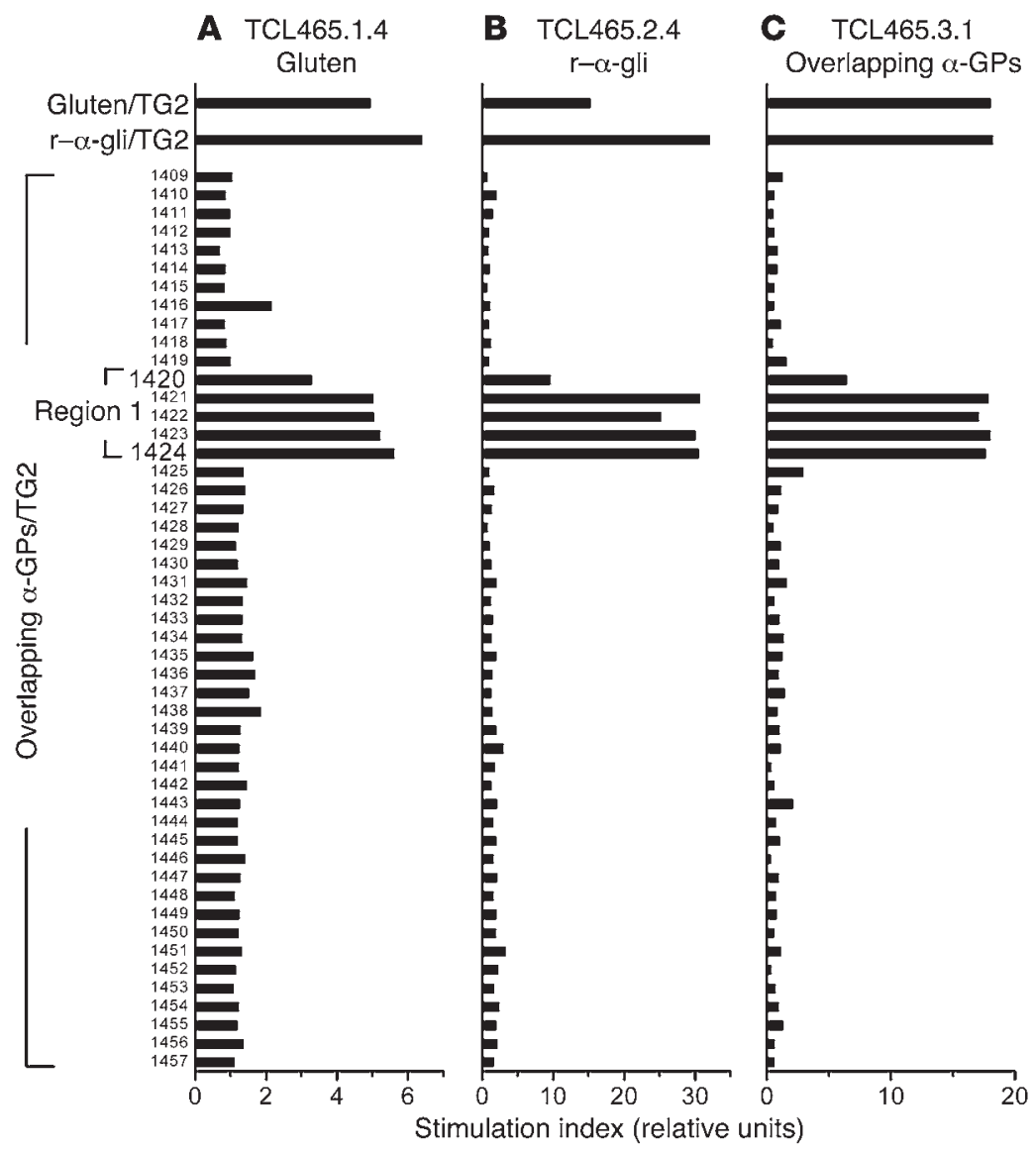

\section{Figure 1}

Testing of T cell lines (TCL) isolated from biopsy specimens of a DQ2+DQ8+ patient (CD465) stimulated in parallel with (A) chymotrypsin-treated gluten, (B) chymotrypsin-treated recombinant AJ133612 $\alpha$-gliadin, and (C) overlapping AJ133612 $\alpha$-gliadin peptides against the whole panel of TG2-treated AJ133612 $\alpha$-gliadin peptides (1409-1457). Peptides were tested at $10 \mu \mathrm{M}$, and CD114 (DQA $\left.{ }^{*} 0501 / D Q B 1{ }^{*} 0201\right) \mathrm{B}$ lymphoblastoid cells were used as APCs. TG2-treated gluten and TG2-treated recombinant AJ133612 $\alpha$-gliadin were used as positive controls. Responses are given as the stimulation index. $\alpha$-GPs, $\alpha$-gliadin peptides; $r-\alpha$-gli, recombinant $\alpha$-gliadin.
This peptide was also subjected to analysis by ESI-MS, which demonstrated an average deamidation of 1.4 residues after 4 hours' treatment with TG2. MS/MS analysis revealed selective deamidation at positions 68,71 , and 76 at $45 \%, 15 \%$, and $40 \%$, respectively. We next tested for $\mathrm{T}$ cell recognition synthetic peptides with single $\mathrm{Q} \rightarrow \mathrm{E}$ substitutions at positions 68 (P1), 71 (P4), or 76 (P9) and a peptide with $\mathrm{Q} \rightarrow$ E substitutions at both position 68 and position 76 . We found that the 2 DQ8-restricted clones (TCC544.1.1.2 and TCC544.1.3.2) responded only to peptides with deamidation(s) at 68 and/or 76 (Figure 6, A and B). Both clones recognized the peptide with $\mathrm{Q} \rightarrow \mathrm{E}$ substitutions at both 68 and 76 much better than the peptides with single $\mathrm{Q} \rightarrow \mathrm{E}$ substitutions at 68 or 76 . Peptides singly substituted at 68 or 76 were equally well recognized by both clones. Note that although they were derived from the same patients and had similar reactivity patterns, these 2 clones are not sister clones as they express different TCR V $\beta$ chains (TCC544.1.1.2, TCR V $\beta 17$; TCC544.1.3.2, TCR V $\beta 5.1$ ). In order to determine whether this DQ8-restricted recognition pattern was reflected in polyclonal $\mathrm{T}$ cell lines likely containing $\mathrm{T}$ cells with multiple specificities, we further tested the same peptides for recognition by the $2 \mathrm{~T}$ cell lines from which these clones were established (patient CD544) and a third T cell line from another $\mathrm{DQ}^{+}$patient (CD469). These $\mathrm{T}$ cell lines all displayed the same reactivity pattern, with superior recognition of the peptide with $\mathrm{Q} \rightarrow \mathrm{E}$ substitutions at both 68 and 76 and improved recognition of peptides with $\mathrm{Q} \rightarrow \mathrm{E}$ substitutions at either 68 or 76 (data not shown). By contrast, when testing the DQ2-restricted T cell clones TCC430.1.134 and TCC430.1.145 against the same peptides, these were found to be sensitive to the $\mathrm{Q} \rightarrow$ E substitution at position 71 (Figure 6, C and D). The DQ2-restricted T cells were insensitive to $\mathrm{Q} \rightarrow \mathrm{E}$ substitutions at positions 68 and 76 with the exception of TCC430.1.134, which was slightly sensitive to the $\mathrm{Q} \rightarrow$ E substitution at position 76 (Figure 6D).

In aggregate these results demonstrate that in some instances DQ2- and DQ8-restricted T cells recognize the same gliadin peptides in exactly the same registers, but the DQ2- and DQ8-restricted $T$ cells have different requirements for deamidation. Relating the deamidation pattern of the T cell epitopes with the HLA class II-binding registers, this would fit with deamidation in the relative positions $\mathrm{P} 1, \mathrm{P} 4$, and $\mathrm{P} 9$, suggesting that the DQ8-restricted $\mathrm{T}$ cell clones are sensitive to deamidation at position $\mathrm{P} 1$ and/or $\mathrm{P} 9$ and the DQ2-restricted T cell clones are primarily sensitive to deamidation at position $\mathrm{P} 4$.

$T$ cell recognition of gliadin peptides in the context of DQ2/DQ8 transencoded heterodimers. $T$ cell recognition of the same peptides in the same registers when bound to DQ2 and DQ8 prompted us to investigate whether trans-encoded heterodimers (i.e., $D Q A 1 * 03$ / $D Q B 1 * 02$ and $D Q A 1 * 05 / D Q B 1 * 0302)$ are able to present gliadin peptides to T cells. As APCs we used B lymphoblastoid cell lines, including an HLA class II-negative cell line transfected with $D Q A 1 * 05$ and $D Q B 1 * 0302$, the homozygous cell line 9102, expressing the $D Q A 1 * 03$ and $D Q B 1 * 02$ alleles, and homozygous DQ2- $(D Q A 1 * 05 / D Q B 1 * 02)$ and DQ8-expressing cells (DQA1*03/ $D Q B 1 * 0302)$. The expression of HLA-DQ molecules by these cell lines was analyzed by flow cytometry (Supplemental Figure 1; available online with this article; doi:10.1172/JCI27620DS1). 


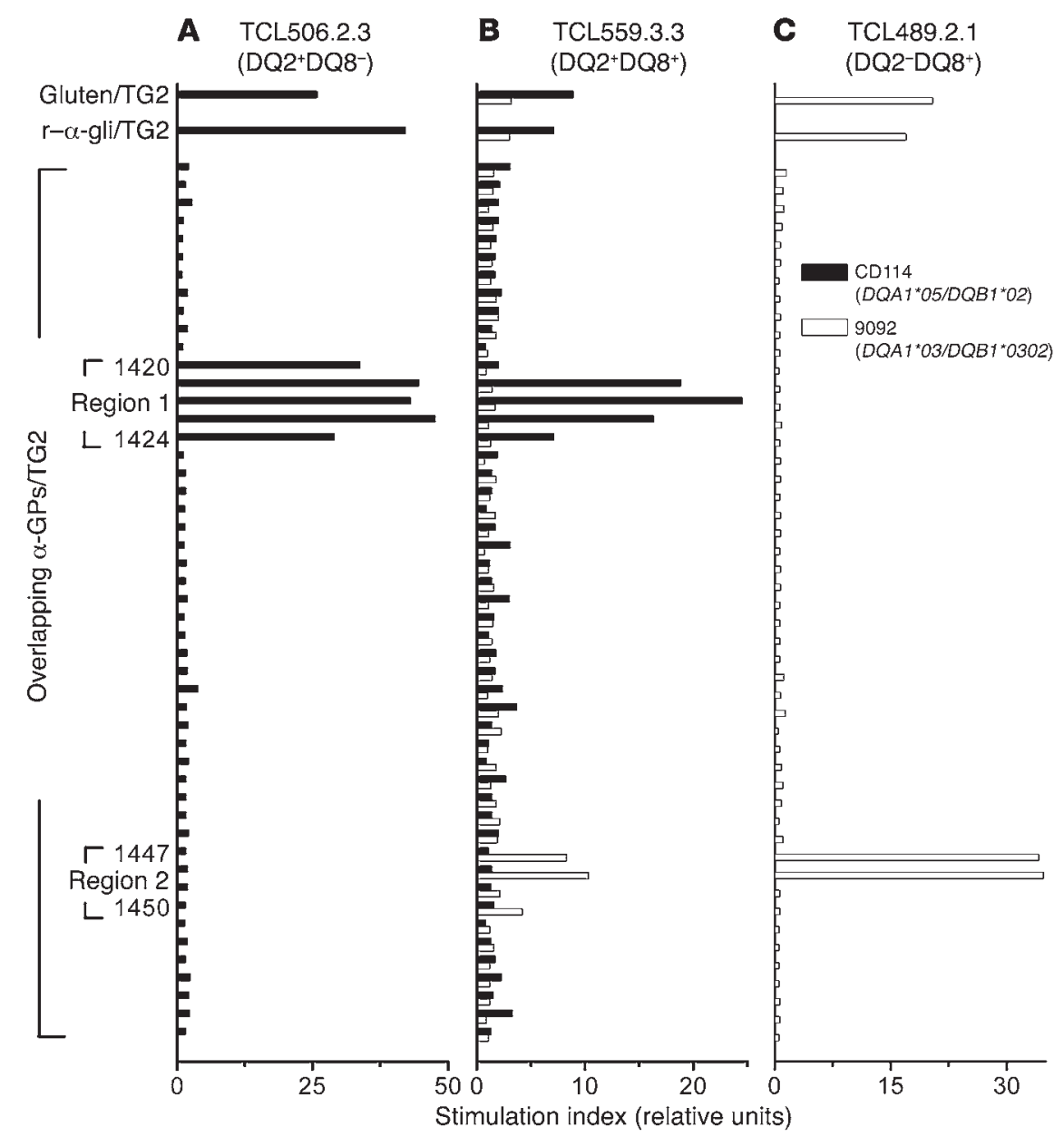

\section{Figure 2}

T cell lines derived from biopsy specimens of 3 different patients stimulated with chymotrypsin-treated recombinant AJ133612 $\alpha$-gliadin were tested against the panel of TG2-treated AJ133612 $\alpha$-gliadin peptides as in Figure 1. Patient CD506 is DQ2+DQ8- (A), patient $\mathrm{CD} 559$ is $\mathrm{DQ}^{+}{ }^{+} \mathrm{DQ}^{+}(\mathrm{B})$, and patient CD489 is DQ2-DQ8+ (C). TG2-treated gluten and TG2-treated recombinant AJ133612 $\alpha$-gliadin were used as positive controls. Black bars (CD114 cells as APCs) indicate DQ2-restricted $T$ cell responses, and white bars (9092 cells as APCs) indicate DQ8restricted responses.
We tested the T cell clones TCC387.19 (DQ2- $\gamma$-VII-specific), TCC544.1.3.2 (DQ8- $\gamma$-I-specific), TCC544.1.1.2 (DQ8- $\gamma$-I-specific), TCC430.1.142 (DQ2- $\alpha$-I-specific), and TCC450.2.2.6 (DQ2$\alpha$-II-specific) in these experiments. Notably, the cells expressing either $D Q A 1 * 03 / D Q B 1 * 02$ or $D Q A 1 * 05 / D Q B 1 * 0302$ were able to present gliadin peptides to some of the T cell clones, demonstrating that both trans-encoded heterodimers are functional for antigen presentation. In particular, the clone TCC387.19 gave an interesting response pattern when tested against variants of the peptide ${ }^{63} \mathrm{PQTQQPQQPFPQPQ}{ }^{76}$ with $\mathrm{Q} \rightarrow$ E substitutions at $\mathrm{P} 1, \mathrm{P} 4$, or $\mathrm{P} 1 / \mathrm{P} 4$ (Figure $7 \mathrm{~A})$. None of these peptides were recognized in the context of $D Q A 1 * 03 / D Q B 1 * 0302$ or $D Q A 1 * 05 /$ $D Q B 1 * 0302$, but the peptides with $\mathrm{Q} \rightarrow \mathrm{E}$ substitutions at $\mathrm{P} 4$ and $\mathrm{P} 1 / \mathrm{P} 4$ were recognized in the context of $D Q A 1 * 05 / D Q B 1 * 02$, and the peptide with $\mathrm{Q} \rightarrow \mathrm{E}$ substitutions at $\mathrm{P} 1, \mathrm{P} 4$, and $\mathrm{P} 1 / \mathrm{P} 4$ were recognized in the context of $D Q A 1 * 03 / D Q B 1 * 02$. Interest-

\section{Figure 3}

Testing for T cell recognition of variants of the ${ }^{228}$ SGQGSFQPSQQN$\mathrm{PQ}^{241}$ peptide of AJ133612 $\alpha$-gliadin. The peptide harbors the DQ8- $\alpha-I$ epitope. A peptide with the native sequence and peptides with $Q \rightarrow E$ substitutions in P1 (position 230), P9 (position 238), and P1/P9 were tested for their ability to stimulate $2 \mathrm{DQ} 8$-restricted $\mathrm{T}$ cell clones, TCC489.2.1.4 (A) and TCC360-HTLR8 (B), which were derived from 2 different DQ2-DQ8+ patients. Responses are shown as $\mathrm{cpm} \times 10^{3}$. TG2-treated, native sequence treated with TG2, used as a control. ingly, the P1/P4 substituted peptide was recognized at a concentration approximately 3 logs lower in the context of $D Q A 1 * 03$ / $D Q B 1 * 02$ compared with $D Q A 1 * 05 / D Q B 1 * 02$, suggesting more efficient antigen presentation by the former heterodimer encoded in trans in DQ2/DQ8 heterozygous individuals. The T cell

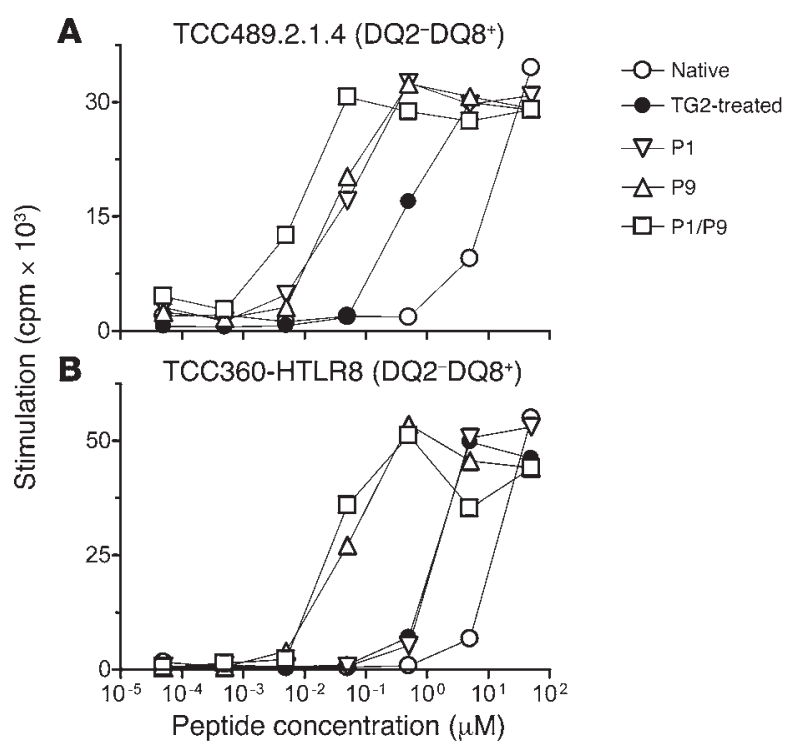


Table 3

T cell responses to TG2-treated, overlapping M36999 $\gamma$-gliadin peptides in intestinal T cell lines derived from 9 adult CD patients

\begin{tabular}{|c|c|c|c|c|c|c|c|c|c|c|c|c|c|c|c|c|c|}
\hline Patient & Stimulant & 1370 & 1371 & 1372 & 1373 & \multirow[t]{2}{*}{1374} & 1375 & \multirow[t]{2}{*}{1376} & \multirow[t]{2}{*}{1377} & \multirow[t]{2}{*}{1378} & \multirow[t]{2}{*}{1379} & \multirow[t]{2}{*}{1380} & \multirow[t]{2}{*}{1381} & \multirow[t]{2}{*}{1382} & \multirow[t]{2}{*}{1383} & \multirow[t]{2}{*}{1388} & \multirow[t]{2}{*}{1391} \\
\hline DQ2+DQ & & & & & & & & & & & & & & & & & \\
\hline CD493 & Gluten & $+\mathrm{DQ2}$ & & & & & +DQ2 & & & & $+\mathrm{DQ} 2$ & $+\mathrm{DQ2}$ & & & & & \\
\hline CD506 & Gluten & $+\mathrm{DQ2}$ & $+\mathrm{DQ} 2$ & $+\mathrm{DQ} 2$ & $+\mathrm{DQ2}$ & $+\mathrm{DQ} 2$ & +DQ2 & $+\mathrm{DQ2}$ & $+\mathrm{DQ2}$ & $+\mathrm{DQ} 2$ & $+\mathrm{DQ} 2$ & $+\mathrm{DQ} 2$ & $+\mathrm{DQ2}$ & & & & \\
\hline \multicolumn{18}{|c|}{$\mathrm{DQ2}^{+} \mathrm{DQ8}^{+}$} \\
\hline CD465 & Gluten & & & & & & & & + DQ8 & +DQ8 & +DQ8 & $+\mathrm{DQ} 2$ & & & & & \\
\hline CD546 & $\gamma$-GPs & $+\mathrm{DQ2}$ & & & & & +DQ2 & & $+\mathrm{DQ8}$ & +DQ8 & & $+\mathrm{DQ2}$ & $+\mathrm{DQ8}$ & & & & \\
\hline CD548 & Gluten & $+\mathrm{DQ2}$ & & & & & $+\mathrm{DQ} 2$ & +DQ2 & & & & $+\mathrm{DQ} 2$ & $+\mathrm{DQ8}$ & & & & \\
\hline CD559 & $\begin{array}{l}\gamma \text {-GPs } \\
\gamma \text {-GPs }\end{array}$ & $\begin{array}{l}+\mathrm{DQ2} \\
+\mathrm{DQ2}\end{array}$ & & & $+\mathrm{DQ} 2 / 8$ & & $\begin{array}{c}+\mathrm{DQ2} \\
+\mathrm{DQ2} / 8\end{array}$ & $+\mathrm{DQ} 2 / 8$ & $\begin{array}{c}+\mathrm{DQ} 2 / 8 \\
+\mathrm{DQ8}\end{array}$ & $\begin{array}{c}+\mathrm{DQ} 2 / 8 \\
+\mathrm{DQ8}\end{array}$ & $\begin{array}{c}+\mathrm{DQ2} \\
+\mathrm{DQ2} / 8\end{array}$ & $\begin{array}{l}+\mathrm{DQ2} \\
+\mathrm{DQ2}\end{array}$ & $\begin{array}{c}+\mathrm{DQ} 2 / 8 \\
+\mathrm{DQ8} 8\end{array}$ & +DQ8 & +DQ8 & $+\mathrm{DQ} 2$ & $+\mathrm{DQ} 2$ \\
\hline \multicolumn{18}{|c|}{ DQ2-DQ8+ } \\
\hline CD469 & Gluten & & & & & & & & $+\mathrm{DQ8}$ & +DQ8 & +DQ8 & & & & & & \\
\hline CD489 & Gluten & $+D Q 8$ & & & +DQ8 & & & & & & & & & & & & \\
\hline CD544 & Gluten & +DQ8 & & & +DQ8 & & +DQ8 & & $+\mathrm{DQ8}$ & +DQ8 & +DQ8 & & $+\mathrm{DQ8}$ & & & & \\
\hline
\end{tabular}

Shown are positive T cell responses restricted by DQ2 (+DQ2) and DQ8 (+DQ8) as well as responses with both DQ2- and DQ8-expressing APCs (+DQ2/8). Only the peptides of M36999 $\gamma$-gliadin that elicited a positive T cell response are indicated. $\gamma$-GPs, $\gamma$-gliadin peptides.

clone TCC544.1.1.2, when tested against variants of the peptide ${ }^{66} \mathrm{FPQQPQQPYPQQPQQ}{ }^{80}$ with $\mathrm{Q} \rightarrow \mathrm{E}$ substitutions at P1, P4, $\mathrm{P} 9, \mathrm{P} 1 / \mathrm{P} 9$, or $\mathrm{P} 1 / \mathrm{P} 4 / \mathrm{P} 9$, recognized the $\mathrm{P} 9$ substituted peptide in the context of $D Q A 1 * 05 / D Q B 1 * 0302$ as well as the P1, P9, P1/P9, and $\mathrm{P} 1 / \mathrm{P} 4 / \mathrm{P} 9$ substituted peptides in the context of $D Q A 1 * 03 /$ $D Q B 1 * 0302$ (Figure 7B). The T cell clones TCC430.1.142 (DQ2$\alpha$-I specific), tested against the peptide QLQPFPQPELPY, and TCC450.2.2.6 (DQ2- $\alpha$-II-specific), tested against the peptide PQPELPYPQPQLPY, responded only when the peptides were presented in the context of $D Q A 1 * 05 / D Q B 1 * 02$ and not in the context of $D Q A 1 * 03 / D Q B 1 * 0302, D Q A 1 * 05 / D Q B 1 * 0302$, or $D Q A 1 * 03 / D Q B 1 * 02$ (data not shown). This may suggest that neither of the trans-encoded heterodimers is effective in presenting gluten epitopes with a proline residue at $\mathrm{P} 1$.

\section{Discussion}

This study demonstrates that DQ2 and DQ8 have preference for binding peptides with negatively charged anchor residues, but that the 2 HLA molecules employed different criteria for selection of deamidated gluten $T$ cell epitopes. This can result in the selection of distinct epitopes localized in different regions of a gliadin protein, but it can also result in the selection of epitopes that combine the DQ2 and DQ8 signatures and are recognized in exactly the same binding register when bound to DQ2 or DQ8. These findings further expand our understanding of the mechanisms underlying the HLA association in celiac disease. Moreover, our observation - which we believe to be novel - that DQ heterodimers, which are encoded in trans in DQ2/DQ8 heterozygotes are functional for antigen presentation and that peptides that combine the DQ2 and

\section{Figure 4}

Testing of $T$ cell lines isolated from biopsy specimens of a DQ2+DQ8+ patient (CD548) stimulated in parallel with chymotrypsin-treated gluten (A) and overlapping M36999 $\gamma$-gliadin peptides (B) against the panel of TG2-treated M36999 peptides (1369-1527). Peptides were tested at $10 \mu \mathrm{M}$. TG2-treated gluten was used as a positive control. Black (CD114 cells as APCs) and white bars (9092 cells as APCs) indicate DQ2-restricted and DQ8-restricted T cell responses, respectively.
DQ8 binding signatures can be presented by such trans-encoded dimers to $T$ cells have relevance for understanding the molecular basis of the HLA association in type 1 diabetes.

The superimposable reactivity patterns toward the peptide panels of the $\mathrm{T}$ cell lines established by stimulation of biopsies with chymotrypsin-digested whole gluten, chymotrypsin-digested recombinant gliadin, or the collection of overlapping peptides indi-

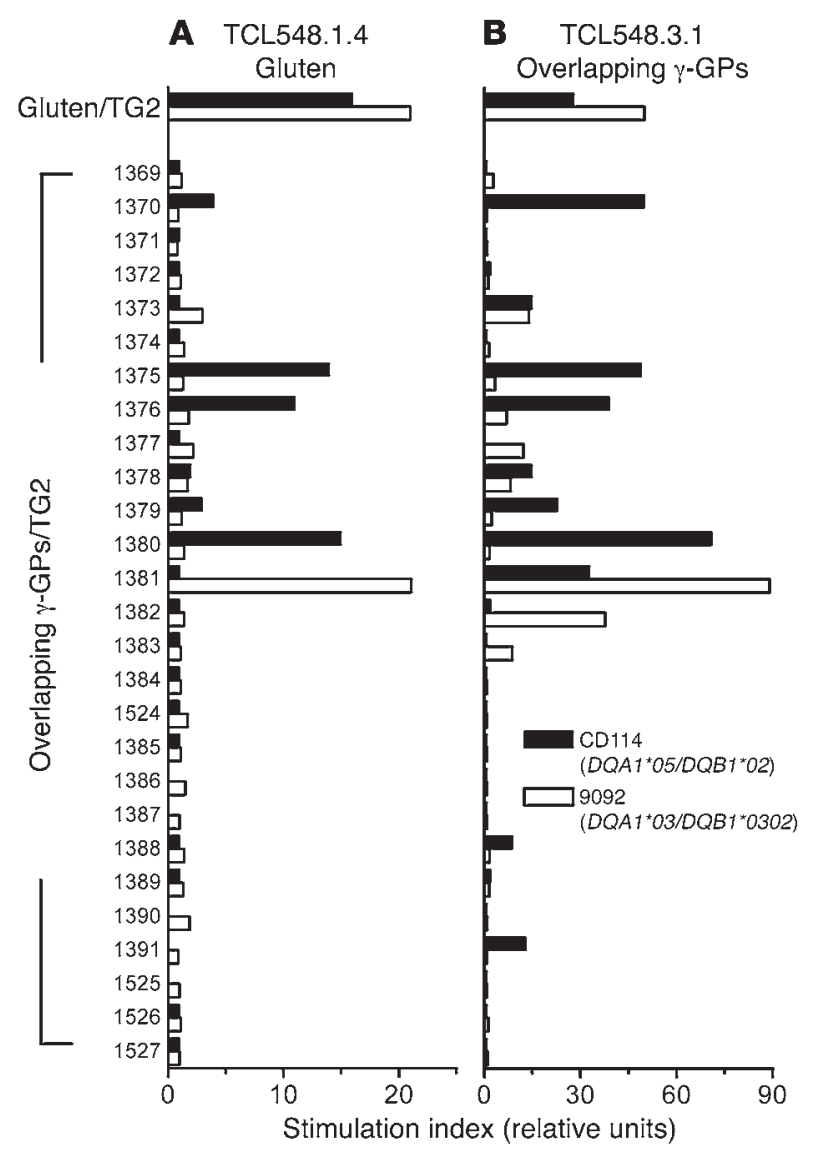


A $\quad$ TCC544.1.1.2 (DQ2-DQ8 $\left.{ }^{+}\right)$

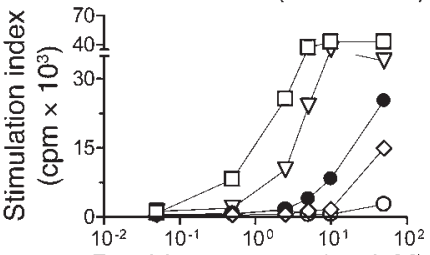

Peptide concentration $(\mu \mathrm{M})$

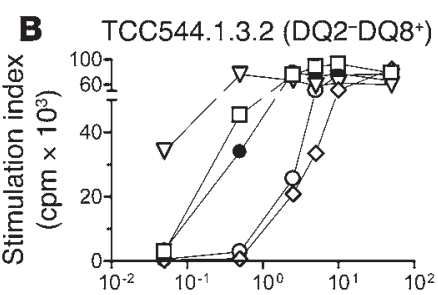

Peptide concentration $(\mu \mathrm{M})$

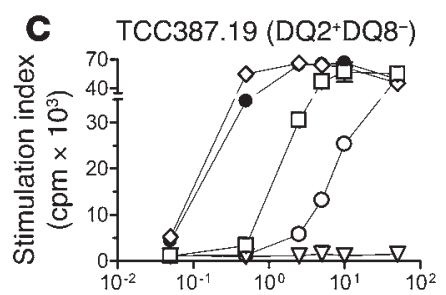

Peptide concentration $(\mu \mathrm{M})$
O- Native $(61-80)$

- TG2-treated (61-80)

$\neg-P 1(63-76)$

$\checkmark-P 4(63-76)$

$\square-P_{1 / P 4}(63-76)$

\section{Figure 5}

T cell recognition of variants of the ${ }^{61}$ QFPQTQQPQQPFPQPQQTFP80 peptide of M36999 $\gamma$-gliadin. The peptide harbors the DQ2- $\gamma$-VII and DQ8- $\gamma$-I epitopes. A peptide with the native sequence and shorter peptides (aa 63-76) with Q $\rightarrow$ E substitutions in P1 (position 66), P4 (position 69), and P1/P4 were tested for their ability to stimulate 2 DQ8-restricted T cell clones (A and B) and 1 DQ2-restricted T cell clone (C). TCC544.1.1.2 (TCR V $\beta 17$ ) and TCC544.1.3.2 (TCR V 35.1 ) originate from a DQ2-DQ8+ CD patient. TCC387.19 originates from a DQ2+DQ8patient. Responses are shown as $\mathrm{cpm} \times 10^{3}$.

cate that there is no bias in our detection of epitopes. In AJ133612 $\alpha$-gliadin, the DQ2- and DQ8-restricted T cell responses were localized to 2 different regions of the protein (regions 1 and 2). This observation suggested that the DQ2 and DQ8 molecules select for different epitopes. The overlapping recognition patterns of M36999 $\gamma$-gliadin peptides by DQ2- and DQ8-restricted T cell lines were therefore surprising. However, further analysis with $\mathrm{T}$ cell clones revealed that the DQ2- and DQ8-restricted T cells recognized different features of the M36999 $\gamma$-gliadin peptides. We found DQ8-restricted $\mathrm{T}$ cell clones that were reactive to peptides harboring the sequence QQPQQPFPQ following TG2 treatment. This sequence is expressed in 4 of the individual M36999 peptides, and reactivity to this epitope is a major contributor to the observed DQ8-associated reactivity pattern of the polyclonal $\mathrm{T}$ cell lines. The QQPQQPFPQ sequence is identical to the core region of the previously characterized DQ2- $\gamma$-VII epitope. The DQ2- and DQ8restricted $\mathrm{T}$ cells recognized this peptide in the same register, but with different requirements for deamidation. A similar sequence, QQPQQPYPQ, is found in another $\gamma$-gliadin (AJ416339), and this is the core sequence of the previously characterized DQ2- $\gamma$-III epitope. We found that the DQ8-restricted T cell clones also recognized TG2-treated peptides harboring this sequence. Again the requirements for deamidation were found to be different for the DQ2- and DQ8-restricted T cell clones, following the same pattern as for the QQPQQPFQ sequence. For the DQ2-restricted $\mathrm{T}$ cells, deamidation at position $\mathrm{P} 4$ was mandatory for recognition, whereas for the DQ8-restricted T cells, deamidation at positions $\mathrm{P} 1$ and/or P9 were important for recognition.

The criteria employed by DQ2 and DQ8 molecules for selecting epitopes were seen from alignment of the core regions of DQ2and DQ8-restricted gliadin epitopes (Table 4). Both DQ2 and DQ8 have a preference for binding of negatively charged residues. For the DQ2-restricted gluten T cell epitopes, glutamate residues formed by TG2-mediated deamidation were found in P1, P4, P6, P7, and P9, but only deamidation in P4 and P6 - and, rarely, P7 seem to be crucial for T cell recognition (19). For the DQ8-restricted gluten $T$ cell epitopes, glutamate residues formed by TG2 were found in positions $\mathrm{P} 1, \mathrm{P} 4$, and $\mathrm{P}$, but in contrast to DQ2, only deamidations in the positions $\mathrm{P} 1$ and/or P9 are critical for T cell recognition. This preference for binding of negatively charged residues in the positions $\mathrm{P} 1$ and $\mathrm{P} 9$ is consistent with other studies of the DQ8 binding motif (11-13). It is striking that, for both DQ2- and DQ8-restricted T cells, it is deamidation at positions with presumed orientation of the side chains toward the MHC that affects $\mathrm{T}$ cell recognition. Notably, the peptide binding preferences we observed for DQ8 and DQ2 are in accordance with the $\mathrm{X}$-ray crystal structures of these molecules (28-30).

DQ2 binds gluten peptides with the proline residues localized in P1, P3, P5, P6, and P8 but not in P2, P4, P7, or P9 $(29,31)$. This pattern is similar for $\mathrm{DQ} 8$, which bind peptides with proline residues in P3, P6, and P8 (Table 4). An important difference between DQ2 and DQ8, however, is at P1. In most MHC class II molecules, including DQ8, there is a hydrogen bond between the amide nitrogen of the P1 residue and the backbone carbonyl of residue $\alpha 53$ $(28,32)$. This appears not to be the case for DQ2. A deletion of the $\alpha 53$ residue of $D Q A 1 * 05$ possibly prevents the establishment of a hydrogen bond to the $\mathrm{P} 1$ amide, and proline residues can thereby be accommodated at P1 without penalty $(29,31)$. The majority of

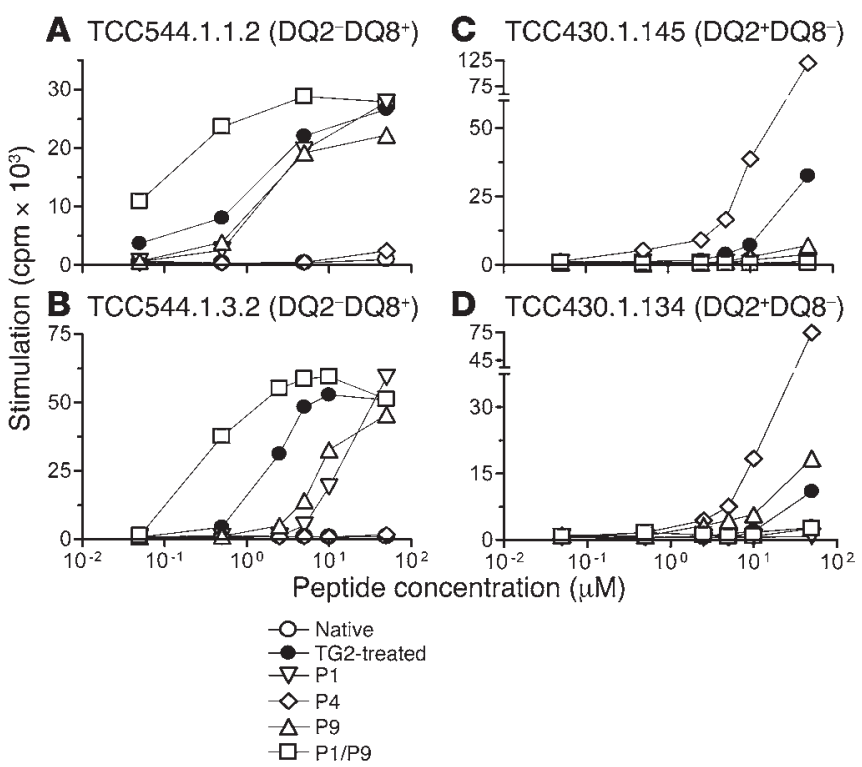

Figure 6

T cell recognition of variants of the ${ }^{66} \mathrm{FPQQPQQPYPQQPQQ} 80$ peptide of AJ416339 $\gamma$-gliadin. The peptide harbors the DQ2- $\gamma$-III and DQ8- $-\gamma-I$ epitopes. A peptide with the native sequence and peptides with $Q \rightarrow E$ substitutions in positions P1 (position 68), P4 (position 71), P9 (position 76), and P1/P9 were tested for their ability to stimulate 2 DQ8restricted $T$ cell clones (A and $\mathbf{B}$ ) and 2 DQ2-restricted T cell clones (C and D). TCC430.1.145 (TCR V $\beta 2$ ) and TCC430.1.134 (TCR V $\beta 2$ ) originate from a DQ2+DQ8- patient. Responses are given in $\mathrm{cpm} \times 10^{3}$. 
A $\operatorname{TCC} 387.19$ (DQ2+DQ8-)

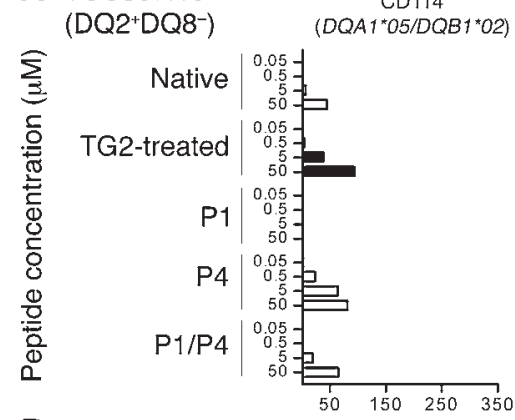

CD114

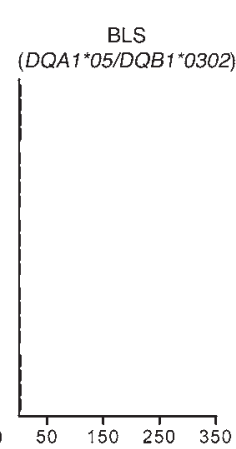

9102

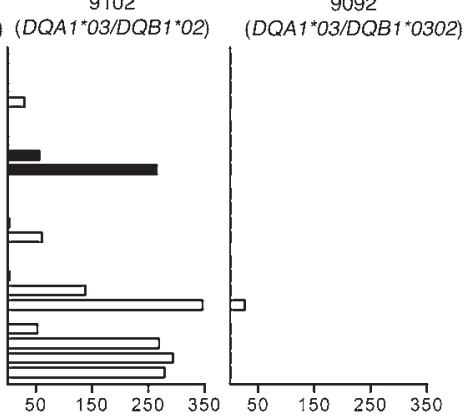

B TCC544.1.1.2

(DQ2 DQ8
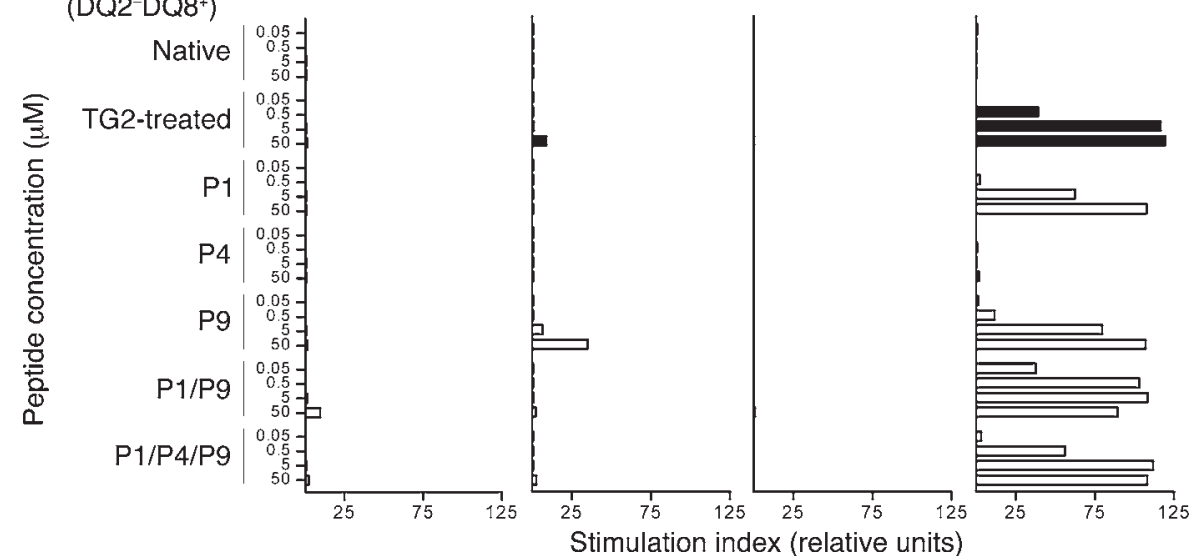

\section{Figure 7}

$\mathrm{T}$ cell recognition of peptides presented by cis- and trans-encoded DQ heterodimers. (A) Recognition of variants of

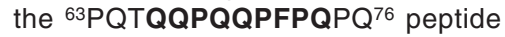
(described in Figure 5 ) by the T cell clone TCC387.19. (B) Recognition of variants of the ${ }^{66} \mathrm{FPQQPQQPYPQQPQQ}{ }^{80}$ peptide (described in Figure 6) by the $T$ cell clone TCC544.1.1.2. the characterized DQ2-restricted gluten T cell epitopes have proline residues at $\mathrm{P} 1$. These epitopes would likely be unavailable for binding to DQ8 in the same binding register, and the inability of the tested DQ2- $\alpha$-I- or DQ2- $\alpha$-II-restricted T cell clones to recognize their epitopes in the context of $D Q A 1 * 03 / D Q B 1 * 02$ gives support to this notion. The fact that DQ2 is better suited than DQ8 to bind the proline-rich gluten peptides that survive gastrointestinal digestion may be the reason why DQ2 is a stronger susceptibility determinant for celiac disease than DQ8.

Celiac disease and type 1 diabetes are both associated with DQ2 $(D Q A 1 * 05 / D Q B 1 * 02)$ and DQ8 $(D Q A 1 * 03 / D Q B 1 * 0302)(24,25)$. In celiac disease, the major susceptibility factor is DQ2, whereas DQ8 adds a small risk independent of DQ2 (3). In type 1 diabetes, DQ8 is a stronger susceptibility factor than DQ2, and the risk associated with DQ2/DQ8 heterozygosity supersedes the combined risks associated with DQ2 and DQ8 $(22,24,27)$. This has led to the hypothesis that trans-encoded dimers, i.e., $D Q A 1 * 05 /$ $D Q B 1 * 0302$ and $D Q A 1 * 03 / D Q B 1 * 02$, are more effective to present diabetogenic epitope(s) to T cells (33). Both the $D Q A 1 * 05 /$ $D Q B 1 * 0302$ and the $D Q A 1 * 03 / D Q B 1 * 02$ dimers are shown to be expressed by DR3-DQ2/DR4-DQ8 heterozygous cells (34). Which epitopes are involved in human type 1 diabetes and what characteristics they should have are basically unknown, although there are suggestions in the literature (35-37), including posttranslationally modified antigens (38). There is no existing evidence for a role of TG 2 in the pathogenesis of type 1 diabetes by deamidating antigens, although this possibility cannot be excluded either. The molecular understanding of HLA association in celiac disease has made huge advances in recent years, much of it because of the identification of disease-relevant gluten cell epitopes. A similar advance has not taken place for type 1 diabetes, and an obvious obstacle is the lack of knowledge of disease-relevant $\mathrm{T}$ cell epitopes; to define them is a major goal. The gluten epitopes recognized by intestinal $T$ cells of celiac disease patients are naturally selected by DQ2 and DQ8 and they are disease relevant. Thus this model system has advantages over transgenic mouse systems, in which the $T$ cell epitopes studied are often the result of forced immunization with the use of adjuvants.

The trans-encoded heterodimers can possibly present a unique peptide or set of peptides. Alternatively, a peptide or limited set of peptides that could be presented by both DQ2 and DQ8 could be even more effectively presented by the trans-encoded heterodimers. The findings of this study provide support for the latter model, as we demonstrated the existence of sequence-related peptides that bound to DQ2 and DQ8 in the same registers and did so by incorporating both the DQ2 and the DQ8 binding motifs. Of particular interest is our observation that a peptide with glutamate residues at $\mathrm{P} 1$ and $\mathrm{P} 4$ was presented more effectively by 3 logs in the context of $D Q A 1 * 03 / D Q B 1 * 02$ than in the context of $D Q A 1 * 05 / D Q B 1 * 02$, presumably because the $\mathrm{P} 1$ pocket of the $D Q A 1 * 03 / D Q B 1 * 02 \mathrm{~mol}$ ecule better accommodates the negatively charged glutamate side chain. We cannot exclude the possibility that this effect is mediated at the level of the TCR, and future work needs to corroborate this notion by peptide binding analysis. Moreover, our testing of $T$ cell recognition of peptides in the context of the trans-encoded heterodimers was suboptimal, as we used $\mathrm{T}$ cell clones that were screened and selected for their ability to recognize peptides in the context of encoded DQ2 or DQ8. Screening T cell clones from DQ2/DQ8 heterozygous individuals that recognize peptides in the context of $D Q A 1 * 05 / D Q B 1 * 0302$ or $D Q A 1 * 03 / D Q B 1 * 02$ should 


\section{Table 4}

Alignment of the core region of 5 DQ2-restricted and 2 DQ8restricted gliadin epitopes

\begin{tabular}{lcccccccccc} 
HLA & Gliadin & \multicolumn{1}{c}{ Peptide-binding register, P1-P9 } \\
restriction & epitope & $\mathbf{1}$ & $\mathbf{2}$ & $\mathbf{3}$ & $\mathbf{4}$ & $\mathbf{5}$ & $\mathbf{6}$ & $\mathbf{7}$ & $\mathbf{8}$ & $\mathbf{9}$ \\
DQ2 & $\alpha-I$ & $\mathrm{P}$ & $\mathrm{F}$ & $\mathrm{P}$ & $\mathrm{Q}$ & $\mathrm{P}$ & $\mathrm{E}$ & $\mathrm{L}$ & $\mathrm{P}$ & $\mathrm{Y}$ \\
& $\alpha-I I$ & $\mathrm{P}$ & $\mathrm{Q}$ & $\mathrm{P}$ & $\mathrm{E}$ & $\mathrm{L}$ & $\mathrm{P}$ & $\mathrm{Y}$ & $\mathrm{P}$ & $\mathrm{Q}$ \\
& $\gamma-I$ & $\mathrm{P}$ & $\mathrm{Q}$ & $\mathrm{Q}$ & $\mathrm{S}$ & $\mathrm{F}$ & $\mathrm{P}$ & $\mathrm{E}$ & $\mathrm{Q}$ & $\underline{\mathrm{Q}}$ \\
& $\gamma-I I$ & $\underline{Q}$ & $\mathrm{Q}$ & $\mathrm{P}$ & $\mathrm{E}$ & $\mathrm{Q}$ & $\mathrm{P}$ & $\mathrm{Y}$ & $\mathrm{P}$ & $\underline{\mathrm{Q}}$ \\
& $\gamma-\mathrm{VII}$ & $\underline{\mathrm{Q}}$ & $\mathrm{Q}$ & $\mathrm{P}$ & $\mathrm{E}$ & $\mathrm{Q}$ & $\mathrm{P}$ & $\mathrm{F}$ & $\mathrm{P}$ & $\mathrm{Q}$ \\
$\mathrm{DQ8}$ & $\alpha-I$ & $\mathrm{E}$ & $\mathrm{G}$ & $\mathrm{S}$ & $\mathrm{F}$ & $\mathrm{Q}$ & $\mathrm{P}$ & $\mathrm{S}$ & $\mathrm{Q}$ & $\mathrm{E}$ \\
& $\gamma-I$ & $\mathrm{E}$ & $\mathrm{Q}$ & $\mathrm{P}$ & $\mathrm{Q}$ & $\mathrm{Q}$ & $\mathrm{P}$ & $\mathrm{F}$ & $\mathrm{P}$ & $\mathrm{Q}$ \\
& $\gamma-I$ & $\mathrm{E}$ & $\mathrm{Q}$ & $\mathrm{P}$ & $\underline{\mathrm{Q}}$ & $\mathrm{Q}$ & $\mathrm{P}$ & $\mathrm{Y}$ & $\mathrm{P}$ & $\mathrm{E}$
\end{tabular}

The DQ2- - -III, DQ2- $\gamma$-VII, and DQ8- $\gamma-\mathrm{I}$ epitopes are derived from the same or related sequences of $\gamma$-gliadin. Glutamate residues, which are formed by TG2-mediated deamidation and which are important for recognition by DQ2- or DQ8-restricted T cells, are shown in bold. Additional glutamine residues also targeted by TG2 are underlined. Also note the ordered spacing of the proline residues in the epitopes.

facilitate the characterization of peptides that are selected for presentation by the diabetes-related trans-encoded DQ heterodimers. Whether peptides that carry a negative charge at P6 or P7 in addition to the negative charge at P1 and/or P9 can also be better presented by the $D Q A 1 * 03 / D Q B 1 * 02$ heterodimer is one of the questions that should be addressed.

Our observations also raise the question of why there is no synergistic effect between DQ2 and DQ8 as predisposing elements in celiac disease. This may be explained by the fact that in the overall $T$ cell response to gluten in celiac disease patients, the responses to the DQ2- $\gamma$-III/DQ2- $\gamma$-VII epitopes are minor contributors, whereas the main response is directed against the DQ2- $\alpha-\mathrm{I}, \mathrm{DQ} 2-\alpha-\mathrm{II}$, and DQ2- $\alpha$-III epitopes (19), which as we showed here did not overlap with DQ8-restricted epitopes and for which we have found no evidence for presentation by any of the trans-encoded heterodimers.

In summary, this work give details of antigen presentation by DQ2 and DQ8 molecules that further expand the knowledge of the HLA association in celiac disease and allow us to predict essential features of peptides that are involved in type 1 diabetes.

\section{Methods}

Subjects. Small intestinal biopsies were obtained by gastroduodenoscopy from 12 Norwegian adult celiac disease patients (4 were DQ2 ${ }^{+} \mathrm{DQ} 8-$, 4 were $\mathrm{DQ}^{+}{ }^{-} \mathrm{DQ}^{+}$, and 4 were $\mathrm{DQ} 2-\mathrm{DQ} 8+$ ). The gastroduodenoscopy investigations, part of the patients' routine treatment, were performed to assess histological improvement of disease status after switching to a gluten-free diet. All patients gave written informed consent before the gastroduodenoscopy. The study received approval from the Regional Committee for Medical Research Ethics (Ullevål University Hospital, Oslo, Norway).

Antigens. The preparation and subsequent chymotrypsin treatment of gliadin, gluten, and recombinant AJ133612 $\alpha$-gliadin were performed as described previously $(39,40)$. The peptides were either synthesized using Fmoc/OtBu-chemistry and 2-chlorotrityl resin (Senn Chemicals) or purchased from EZBiolab. The overlapping AJ133612 $\alpha$-gliadin peptides were made as pentadecapeptides overlapping with 10 amino acids. To avoid the formation of disulphide bonds, all the cysteine residues were substituted with alanine. The overlapping M36999 $\gamma$-gliadin peptide was made as eicosapeptides overlapping with 10 amino acids. The amino acid sequence of gliadin peptides that elicited a positive $\mathrm{T}$ cell response are listed in Table 1. Treatment of gluten antigens and peptides with human recombinant TG2 (41) was performed at $37^{\circ} \mathrm{C}$ for 2 hours in PBS and $2 \mathrm{mM} \mathrm{CaCl}_{2}$ using $100-130 \mu \mathrm{g} / \mathrm{ml} \mathrm{TG} 2$.

Antibodies. The mouse mAbs 2.12.E11 (specific for $D Q B 1 * 02)(42)$, IVD12 (specific for $D Q B 1 * 03)$ (43), and SPV-L3 (specific for pan-DQ) (44) as well as the rat mAb SFR20-DQ $\alpha 5$ (specific for DQA1*04/05/06) (45) were used for analysis of HLA-DQ expression. Staining was done with unlabeled primary mAbs except for 2.12.E11, which, in some instances, was used directly labeled with FITC. As secondary antibodies for the mouse mAbs, we used FITC-conjugated Goat Anti-Mouse IgG or FITCconjugated Goat Anti-Mouse IgG1 (SouthernBiotech). SFR20-DQ $\alpha 5$ were detected by biotinylated Mouse Anti-Rat Fc-Ig antibody (Accurate) followed by Streptavidin-PE (Invitrogen). For control staining, mouse unconjugated IgG1 or IgG2a from R\&D Systems and IgG1-FITC from $\mathrm{BD}$ Biosciences - Pharmingen were used. The HLA restriction of the $\mathrm{T}$ cells was determined by testing inhibition of $\mathrm{T}$ cell proliferation in the presence of purified mAb B8.11 (pan-DR), SPV-L3 (pan-DQ), or B7/21 (pan-DP) at a concentration of $10 \mu \mathrm{g} / \mathrm{ml}$.

Flow cytometry and cell sorting. Expression of HLA-DQ molecules was analyzed by a FACSCalibur instrument with CellQuest software (version 4.0; BD Biosciences - Pharmingen). Cell sorting was performed with a FACSAria instrument (BD Biosciences - Pharmingen).

APCs. B lymphoblastoid cells were used as APCs. DQ2+DQ8- responses were tested with the B cell line CD114 (homozygous, DQA1*0501) $D Q B 1 * 0201)$. DQ2-DQ8+ ${ }^{+}$responses were tested with the cell line 9092 (homozygous, $D Q A 1 * 0301 / D Q B 1 * 0302$ ). In addition, for analysis of transencoded heterodimer-mediated presentation we used the homozygous cell line $9102\left(D Q A 1^{*} 0303 / D Q B 1 * 0202\right)$ and an HLA class II-negative Bare Lymphocyte Syndrome (BLS) cell line transfected with $D Q A 1 * 0501$ and $D Q B 1 * 0302$ (46;47). The 9102 cell line, although derived from an original vial distributed through the 11th International Histocompatibility Workshop (IHWS), was initially genotyped to $H L A D Q A 1 * 0104, * 0303, * 0501$ and $D Q B 1 * 02,{ }^{*} 05$, and flow cytometry revealed that it consisted of 2 cell populations. We hence performed cell sorting, selecting for cells positive for 2.12.E11 and negative for SFR20-DQ $\alpha 5$. The purified cell line (>99.5\% purity) was cultured and genotyped to be $H L A A^{*} 03, B * 58, C^{*} 06, D R B 1 * 09$, $D Q A 1 * 0303, D Q B 1 * 0202$. This was consistent with the IHWS HLA typing data for 9102 and verified that we had regenerated the original 9102 cell line. The B lymphoblastoid cell lines were irradiated with $80 \mathrm{~Gy}$ when used in T cell assays, except the BLS transfectant, which in some experiments were irradiated with $150 \mathrm{~Gy}$.

HLA-typing. Subjects were serologically typed by a complement dependent cytotoxicity test with immunomagnetically separated target cells. Some individuals and cell lines were genomically typed using the Olerup SSP HLA kits for DQA1 and DQB1 (GenoVision, QIAGEN) and Dynal RELI SSO HLA kits for A, B, C and DRB1 (Invitrogen). DNA was prepared using GenoPrep Cartridge B (GenoVision, QIAGEN).

Gluten-specific T cells and T cell proliferation assays. T cell reagents were established from intestinal biopsies of the celiac disease patients. Separate, single-biopsy specimens of each subject were challenged with the following antigens: chymotrypsin-treated gluten $(0.2 \mathrm{mg} / \mathrm{ml})$, chymotrypsin-treated recombinant AJ133612 $\alpha$-gliadin $(0.1 \mathrm{mg} / \mathrm{ml})$, and a peptide pool containing all the overlapping AJ133612 $\alpha$-gliadin peptides or the overlapping M36999 $\gamma$-gliadin peptides (10 $\mu \mathrm{M}$ of each peptide). Except for variation in the antigenic challenge of the biopsies the generation of $\mathrm{T}$ cell lines, $\mathrm{T}$ cell cloning and $\mathrm{T}$ cell proliferation assays were performed as described previously $(40,48)$. The assessment of reactivity of the $\mathrm{T}$ cell lines was done in proliferative restimulation assays using DR3 ${ }^{+} \mathrm{DQ} 2^{+}$homozygous or DR4 ${ }^{+} \mathrm{DQ}^{+} \mathrm{B}$ lymphoblastoid cells. Positive $\mathrm{T}$ cell responses were defined as a stimulation index greater than 4 (stimulation index calcu- 
lated as mean cpm in the presence of antigen divided by mean cpm in the absence of antigen). Activated T cells express HLA class II molecules, and to avoid autopresentation of peptides by $\mathrm{T}$ cells as a confounding factor in experiments with $\mathrm{T}$ cells of $\mathrm{DQ} 2^{+} \mathrm{DQ} 8^{+}$individuals, the plates with the APCs and peptides were washed thoroughly prior to the addition of $\mathrm{T}$ cells. $T$ cell clonality was tested by the IOTest Beta mark (Beckman Coulter) TCR V $\beta$ staining kit covering about $70 \%$ of the normal human TCR $\mathrm{V} \beta$ repertoire of $\mathrm{CD}^{+}$lymphocytes.

MS analysis. For analysis by MS, peptides 1367,1375 , and $1378(200 \mu \mathrm{M})$ were treated by TG2 $(100 \mu \mathrm{g} / \mathrm{ml})$ at $37^{\circ} \mathrm{C}$ in Tris/ $\mathrm{HCl}(\mathrm{pH} 7.4)$ and $2 \mathrm{mM}$ $\mathrm{CaCl}_{2}$. For peptides 1367 and 1375 , an identical amount of additional TG2 was added after 2 hours, and the incubation was continued to 4 hours. Peptide 1378 was treated for 1.5 hours. These different incubation times were selected to obtain a similar degree of average deamidation, as determined by pilot kinetic experiments (data not shown). The reaction was stopped by adding iodoacetamide $(5 \mathrm{mM})$, and peptides were desalted on ZipTip columns (Millipore). Equilibration and washing steps were performed with $2 \%$ formic acid in water. Peptides were eluted with $50 \%$ methanol, $49 \%$ water, and $1 \%$ formic acid and were analyzed for deamidation on an electrospray ionization quadrupole-time-of-flight mass spectrometer (Q-Tof Ultima Global; Waters). Samples were sprayed from needles (Protana Inc.) at a capillary voltage of 2,000 V and a cone voltage of $100 \mathrm{~V}$. Collision-induced dissociation was performed on the doubly charged parent ions (collision gas, argon; collision energy, 25-35 electron $\mathrm{V}(\mathrm{eV})$. To quantify the average deamidation of the peptides and the ratio of deamidation between glutamine residues within 1 peptide, signals in the MS and MS/MS spectra were centroided, and the shift of the centroids compared with that of the native peptides and their fragment ions was calculated.

\section{Acknowledgments}

This work is supported by the Research Council of Norway, the European Commission, and the Deutsche Forschungsgemeinschaft. We thank Marie Kongshaug Johannesen, Tore Jensen, and Nicole Sessler for excellent technical assistance; Anne Kari Tveter and Siri Tennebø Flåm for HLA typing; Elin Bergseng for synthesis of a peptide in the laboratory of Chaitan Khosla; Susan Radka for the kind gift of the SFR20-DQ $\alpha 5$ hybridoma; and Erik Thorsby for critical reading of the manuscript. MS was carried out at the Proteomic Unit, University of Bergen (PROBE), Bergen, Norway.

Received for publication December 9, 2005, and accepted in revised form May 30, 2006.

Address correspondence to: Ludvig M. Sollid, Institute of Immunology, University of Oslo, Rikshospitalet-Radiumhospitalet Medical Center, N-0027 Oslo, Norway. Phone: 47-230-73811; Fax: 47-230-73510; E-mail: 1.m.sollid@medisin.uio.no.

Stig Tollefsen and Helene Arentz-Hansen contributed equally to this work.
1. Green, P.H., and Jabri, B. 2003. Coeliac disease. Lancet. 362:383-391.

2. Sollid, L.M. 2000. Molecular basis of celiac disease. Annu. Rev. Immunol. 18:53-81.

3. Sollid, L.M., and Lie, B.A. 2005. Celiac disease genetics: current concepts and practical applications. Clin. Gastroenterol. Hepatol. 3:843-851.

4. Lundin, K.E.A., et al. 1993. Gliadin-specific, HLA$\mathrm{DQ}(\alpha 1 * 0501, \beta 1 * 0201)$ restricted $\mathrm{T}$ cells isolated from the small intestinal mucosa of celiac disease patients. J. Exp. Med. 178:187-196.

5. Molberg, Ø., et al. 1997. Gliadin specific, HLA DQ2-restricted $\mathrm{T}$ cells are commonly found in small intestinal biopsies from coeliac disease patients, but not from controls. Scand. J. Immunol. 46:103-109.

6. Lundin, K.E.A., Scott, H., Fausa, O., Thorsby, E., and Sollid, L.M. 1994. T cells from the small intestinal mucosa of a DR4, DQ7/DR4, DQ8 celiac disease patient preferentially recognize gliadin when presented by DQ8. Hum. Immunol. 41:285-291.

7. Molberg, Ø., et al. 1998. Tissue transglutaminase selectively modifies gliadin peptides that are recognized by gut-derived T cells. Nat. Med. 4:713-717.

8. van de Wal, Y., et al. 1998. Selective deamidation by tissue transglutaminase strongly enhances gliadinspecific T cell reactivity. J. Immunol. 161:1585-1588.

9. Johansen, B.H., Vartdal, F., Eriksen, J.A., Thorsby, E., and Sollid, L.M. 1996. Identification of a putative motif for binding of peptides to HLA-DQ2. Int Immunol. 8:177-182.

10. van de Wal, Y., Kooy, Y.M.C., Drijfhout, J.W., Amons, R., and Koning, F. 1996. Peptide binding characteristics of the coeliac disease-associated $\mathrm{DQ}(\alpha 1 * 0501, \beta 1 * 0201)$ molecule. Immunogenetics. 44:246-253.

11. Kwok, W.W., Domeier, M.L., Raymond, F.C., Byers, P., and Nepom, G.T. 1996. Allele-specific motifs characterize HLA-DQ interactions with a diabetes-associated peptide derived from glutamic acid decarboxylase. J. Immunol. 156:2171-2177.

12. Godkin, A., et al. 1997. Use of eluted peptide sequence data to identify the binding characteristics of peptides to the insulin-dependent diabetes susceptibility allele HLA-DQ8 (DQ 3.2). Int. Immunol. 9:905-911

13. Suri, A., Walters, J.J., Gross, M.L., and Unanue, E.R. 2005. Natural peptides selected by diabetogenic DQ8 and murine I-A(g7)molecules show common sequence specificity. J. Clin. Invest. 115:2268-2276. doi:10.1172/JCI25350.

14. Sjöström, H., et al. 1998. Identification of a gliadin T-cell epitope in coeliac disease: general importance of gliadin deamidation for intestinal T-cell recognition. Scand. J. Immunol. 48:111-115.

15. Arentz-Hansen, H., et al. 2000. The intestinal T cell response to $\alpha$-gliadin in adult celiac disease is focused on a single deamidated glutamine targeted by tissue transglutaminase. J. Exp. Med. 191:603-612.

16. Anderson, R.P., Degano, P., Godkin, A.J., Jewell, D.P., and Hill, A.V. 2000. In vivo antigen challenge in celiac disease identifies a single transglutaminase-modified peptide as the dominant A-gliadin T-cell epitope. Nat. Med. 6:337-342.

17. Vader, W., et al. 2002. The gluten response in children with celiac disease is directed toward multiple gliadin and glutenin peptides. Gastroenterology. 122:1729-1737.

18. Arentz-Hansen, H., et al. 2002. Celiac lesion T cells recognize epitopes that cluster in regions of gliadins rich in proline residues. Gastroenterology. 123:803-809.

19. Qiao, S.W., et al. 2005. Refining the rules of gliadin $T$ cell epitope binding to the disease-associated DQ2 molecule in celiac disease: importance of proline spacing and glutamine deamidation. J. Immunol. 175:254-261.

20. van de Wal, Y., et al. 1998. Small intestinal T cells of celiac disease patients recognize a natural pepsin fragment of gliadin. Proc. Natl. Acad. Sci. U.S. A. 95:10050-10054.

21. van de Wal, Y., et al. 1999. Glutenin is involved in the gluten-driven mucosal $\mathrm{T}$ cell response. Eur. J. Immunol. 29:3133-3139.

22. Svejgaard, A., and Ryder, L.P. 1981. HLA genotype distribution and genetic models of insulin-dependent diabetes mellitus. Ann. Hum. Genet. 45:293-298.
23. Todd, J.A., Bell, J.I., and McDevitt, H.O. 1987. HLA-DQ $\beta$ gene contributes to susceptibility and resistance to insulin-dependent diabetes mellitus. Nature. 329:599-604.

24. Thorsby, E. 1997. Invited anniversary review: HLA associated diseases. Hum. Immunol. 53:1-11.

25. Nepom, G.T., and Erlich, H. 1991. MHC class-II molecules and autoimmunity. Annu. Rev. Immunol. 9:493-525.

26. Redondo, M.J., and Eisenbarth, G.S. 2002. Genetic control of autoimmunity in type I diabetes and associated disorders. Diabetologia. 45:605-622.

27. Koeleman, B.P.C., et al. 2004. Genotype effects and epistasis in type 1 diabetes and HLA-DQ trans dimer associations with disease. Genes Immun. 5:381-388.

28. Lee, K.H., Wucherpfennig, K.W., and Wiley, D.C. 2001. Structure of a human insulin peptide-HLADQ8 complex and susceptibility to type 1 diabetes. Nat. Immunol. 2:501-507.

29. Kim, C.Y., Quarsten, H., Bergseng, E., Khosla, C., and Sollid, L.M. 2004. Structural basis for HLA-DQ2mediated presentation of gluten epitopes in celiac disease. Proc. Natl. Acad. Sci. U. S. A. 101:4175-4179.

30. Jones, E.Y., Fugger, L., Strominger, J.L., and Siebold, C. 2006. MHC class II proteins and disease: a structural perspective. Nat. Rev. Immunol. 6:271-282.

31. Bergseng, E., Xia, J., Kim, C.Y., Khosla, C., and Sollid, L.M. 2005. Main chain hydrogen bond interactions in the binding of proline-rich gluten peptides to the Celiac disease-associated HLA-DQ2 molecule. J. Biol. Chem. 280:21791-21796.

32. Nelson, C.A., and Fremont, D.H. 1999. Structural principles of MHC class II antigen presentation. Rev. Immunogenet. 1:47-59.

33. Nepom, B.S., Schwarz, D., Palmer, J.P., and Nepom, G.T. 1987. Transcomplementation of HLA genes in IDDM. HLA-DQ $\alpha$ - and $\beta$-chains produce hybrid molecules in DR3/4 heterozygotes. Diabetes. 36:114-117.

34. Kwok, W.W., Kovats, S., Thurtle, P., and Nepom, G.T. 1993. HLA-DQ allelic polymorphisms constrain patterns of class II heterodimer formation. J. Immunol. 150:2263-2272. 
35. Peakman, M., et al. 2001. Characterization of preparations of GAD65, proinsulin, and the islet tyrosine phosphatase IA-2 for use in detection of autoreactive T-cells in type 1 diabetes: report of phase II of the Second International Immunology of Diabetes Society Workshop for Standardization of T-cell assays in type 1 diabetes. Diabetes. 50:1749-1754.

36. Viglietta, V., Kent, S.C., Orban, T., and Hafler, D.A. 2002. GAD65-reactive T cells are activated in patients with autoimmune type 1 a diabetes. J. Clin. Invest. 109:895-903. doi:10.1172/JCI200214114.

37. Kent, S.C., et al. 2005. Expanded T cells from pancreatic lymph nodes of type 1 diabetic subjects recognize an insulin epitope. Nature. 435:224-228.

38. Mannering, S.I., et al. 2005. The insulin A-chain epitope recognized by human $\mathrm{T}$ cells is posttranslationally modified. J. Exp. Med. 202:1191-1197.

39. Arentz-Hansen, E.H., McAdam, S.N., Molberg, $\varnothing$., Kristiansen, C., and Sollid, L.M. 2000. Production of a panel of recombinant gliadins for the characterisation of T cell reactivity in coeliac disease. Gut. 46:46-51.

40. Molberg, $\varnothing$., et al. 2003. Intestinal T-cell responses to high-molecular-weight glutenins in celiac disease. Gastroenterology. 125:337-344.

41. Piper, J.L., Gray, G.M., and Khosla, C. 2002. High selectivity of human tissue transglutaminase for immunoactive gliadin peptides: implications for celiac sprue. Biochemistry. 41:386-393.

42. Viken, H.D., et al. 1995. Characterization of an HLA-DQ2-specific monoclonal antibody. Influence of amino acid substitutions in DQ $\beta 1 * 0202$. Hum. Immunol. 42:319-327.

43. Giles, R.C., et al. 1983. Structural analysis of human I-A homologue using a monoclonal antibody that recognizes an MB3-like specificity. J. Exp. Med. 157:1461-1470.

44. Spits, H., Ijssel, H., Thompson, A., and De Vries,
J.E. 1983. Human $\mathrm{T}^{+}$and $\mathrm{T}^{+}$cytotoxic $\mathrm{T}$ lymphocyte clones directed at products of different class II major histocompatibility complex loci. J. Immunol. 131:678-683.

45. Amar, A., et al. 1987. Characterization of specific HLA-DQ $\alpha$ allospecificities by genomic, biochemical, and serologic analysis. J. Immunol. 138:3986-3990.

46. Kwok, W.W., et al. 1988. HLA-DQ molecules form $\alpha-\beta$ heterodimers of mixed allotype. J. Immunol. 141:3123-3127.

47. Reichstetter, S., Kwok, W.W., and Nepom, G.T. 1999. Impaired binding of a DQ2 and DQ8-binding HSV VP16 peptide to a DQA1*0501/DQB1*0302 trans class II heterodimer. Tissue Antigens. 53:101-105.

48. Molberg, Ø., McAdam, S.N., Lundin, K.E.A., and Sollid, L.M. 2000. Studies of gliadin-specific T cells in celiac disease. In Celiac disease. Methods and protocols. M.N. Marsh, editor. Humana. Totowa, New Jersey, USA. 105-124. 